\title{
Chlorophyll and Carotenoid Profile and Enzymatic Activities (Chlorophyllase and Lipoxygenase) in Olive Drupes from the Fruit-setting Period to Harvest Time
}

\author{
M. Nieves Criado, M. José Motilva1, Tomás Ramo, and M. Paz Romero \\ Food Technology Department, CeRTA-TPV, University of Lleida, Av/Alcalde Rovira Roure 191, 25198 \\ Lleida, Spain
}

AdDITIONAL INDEX wORDs. chlorophylls, carotenoids, 'Arbequina', 'Farga', olive development, olive ripening, enzymatic activities

\begin{abstract}
The aim of this study was to monitor the pigment profile and chlorophyllase (Chlase) and lipoxygenase (Lox) activities of olive (Olea europaea L.) drupes during the development of the fruit from 'Arbequina' and 'Farga' in order to find better ways to characterize cultivars such as 'Arbequina' that produce virgin olive oils that are highly appreciated in international markets. 'Farga' was included as a comparative reference. The total pigment content in olive drupes from the two cultivars studied suffered a decrease when the maturation process began, the rate of chlorophyll degradation being more marked than that of the carotenoid pigment. Chlorophyllides $a$ and $b, c i s-\alpha$-carotene, $\beta$-cryptoxanthin, and esterified xanthophylls were detected only in 'Arbequina' fruit. The behavior of the Chlase and Lox activities in both cultivars was different. Chlase activity in olives from 'Farga' was detected only at the end of the pit hardening period, but in the case of 'Arbequina' the presence of dephytilated chlorophyllic derivatives is directly related to a higher Chlase enzymatic activity than that of 'Farga' fruit. Although the level of these enzymatic activities decreased when ripening advanced in both cultivars, in 'Arbequina' both enzymes showed a slight increase of activity at the latest stages of ripening.
\end{abstract}

The olive tree has been cultivated for thousands of years around the Mediterranean. The olive requires a long, hot growing season for the fruit to ripen properly, without late spring frosts to kill the blossoms and sufficient winter chill to ensure fruit differentiation. The olive fruit is a green, fleshy, edible drupe with a more or less oval shape depending on the cultivar, which is used either for the extraction of olive oil or for consumption as table olives (green or black), and is the major lipid component of the Mediterranean diet.

During olive development, structural changes and chemical transformations that affect the different components of the fruit take place inside the drupes. This complex process involves the modification of compartments, loss of cell wall structure, causal softening, and accumulation of carbohydrates (Shulman and Lavee, 1979). The olive fruit grow rapidly in their initial stages, followed by a lag period and thereafter another accelerated period of growth, equivalent to the initial one. Fruit setting is characterized by cellular division and an increase in cell size. After fruit set, olives grow rapidly for 30 or $40 \mathrm{~d}$, after which time the seed is formed and the pit hardens. After lignification of the pit, fatty acid synthesis begins together with a fast increase in pulp weight coinciding with the increase of the oil content. Finally, during the ripening process, the olive fruit darkens to purple-black at the same time as the oil content increases.

Received for publication 31 Mar. 2005. Accepted for publication 29 Mar. 2006. Acknowledgments: This work was supported by the AGL2001-0550 grants from the Comisión Interministerial de Ciencia y Tecnología (Inter-ministerial Commission on Science and Technology) (CICYT, Spain). We wish to thank Professor Mínguez-Mosquera (Instituto de la Grasa, Spain) for her helpful guidance in relation to the analysis of pigment fraction.

'To whom reprint requests should be addressed; phone: +34 973 702817; fax: +34973 702596; e-mail: motilva@tecal.udl.es
Chlorophylls and carotenoids are the pigments responsible for the color of the developing olive fruit. As ripening progresses, photosynthetic activity decreases and the concentrations of both Chlase and Lox decrease progressively. At the end of the maturation process, the violet, purple, or black color of the olive fruit is due to the formation of anthocyanins (Roca and Mínguez-Mosquera, 2001a). The main enzymes involved in pigment catabolism in chloroplast are Chlase, Lox, and peroxidase (Gallardo-Guerrero et al., 2003; Gandul-Rojas and Mínguez-Mosquera, 1996; Salas et al., 1999; Yamauchi and Minamide, 1985).

The Chlase enzyme (EC 3.1.1.14) catalyzes the hydrolysis of the ester bond of the chlorophyll molecule into chlorophyllide and phytol, suggesting a key role in chlorophyll degradation (Matile and Hörtensteiner, 1999). However, it is unclear whether this enzyme is involved in the biosynthesis or the catabolism of chlorophyll pigments. Aljuburiet al. (1979) found that in greening oranges, Chlase and chlorophyll content increased at the same time. However, in Capsicum annuиm L. fruit, Chlase activity and chlorophyll losses were not correlated (Hornero-Méndez and Mínguez-Mosquera, 2002). Studies with different olive cultivars growing in the south of Spain have shown that during the fruit growth stage, which coincides with chlorophyll synthesis, Chlase was present in the cultivars studied. In the ripening phase, when the content of chlorophylls decrease progressively, Chlase activity in the fruit of 'Hojiblanca' and 'Picual' was low and decreased with senescence, whereas in the fruit of 'Arbequina' there was an increase in this enzyme as maturity progressed (Roca and Mínguez-Mosquera, 2003).

Lox (EC 1.13.11.12) catalyzes the oxidation of fatty acids containing a cis,cis-1-4 pentadiene system (mainly linoleic and linolenic acids) by addition of molecular oxygen to unsaturated fatty acid hydroperoxide (Feussner and Wasternack, 2002). Gal- 
lardo-Guerrero et al. (2003) found a correlation between the major levels of Lox activity and the maximum presence of oxidized chlorophyll pigments during the growth period in 'Gordal' and 'Manzanilla' olive fruit. Additionally, the increase in the proportion of free unsaturated fatty acids with olive fruit ripening creates adequate conditions for Lox action (Uceda and Hermoso, 1997). In this way, the presence of a thylakoid-associated peroxidative activity in olives has been demonstrated in vitro, which performs chlorophyll degradation to $13^{2}$-hydroxychlorophylls $a$ and $b\left(13^{2}\right.$ $\mathrm{OH}-\mathrm{Chl} a$ and $13^{2}-\mathrm{OH}-\mathrm{Chl} b$ ) and suggests the participation of this enzyme system in the formation of these compounds in olives. The peroxidative activity associated with the thylakoid membranes affected not only chlorophylls but also other accessory pigments in the photosynthetic process, such as carotenoids. The reaction of the carotenoids with the peroxy radicals generated during lipid peroxidation sets off a process of oxidation finally leading to pigment decoloration. According with this mechanism, Lox can catalyze carotenoid decoloration indirectly as a consequence of the radical species generated in its specific hydroperoxidation of fatty acids having a cis,cis-1,4-pentadiene structure (GandulRojas et al., 2004).

It is known that pigment compounds in olive drupes are responsible for virgin olive oil color, this being one of the first sensory attributes evaluated by consumers (Pagliarini et al., 1994). From a commercial point of view, different types of oils from the same cultivar can be extracted depending on the time of fruit harvesting. Oils coming from the earliest harvest are greenish in color, grassy and bitter almond-like in taste, while those from the latest harvest are yellow in color, more fluid, with a fruity, often sweetish, flavor.

Thus, this current study was aimed at monitoring the pigment profile and Chlase and Lox activities of olive drupe from 'Arbequina' and 'Farga' during the development of the fruit, from fruit set to harvest time, as well as investigating the relationship between both enzymes and the total chlorophylls and carotenoids. 'Farga' was included as a comparative reference in order to find better ways to characterize cultivars, such as 'Arbequina', that produce virgin olive oils that are highly appreciated in international markets.

\section{Materials and Methods}

Plant Material. The trial was carried out during 2003 in two different olive groves of 'Arbequina' and 'Farga'. The 'Arbequina' fruit were picked in the olive-growing region of Les Garrigues, situated in the province of Lleida (Catalonia, Spain). The climate of this area is Mediterranean with a continental influence, and the average altitude varies between 400 and $450 \mathrm{~m}$ above sea level. The daily and annual temperature variations are greater than in a pure Mediterranean climate, with its maritime influence. The winters are much colder and the summers drier and hotter (actual temperature ranges from a minimum of $-8{ }^{\circ} \mathrm{C}$ to a maximum of $40^{\circ} \mathrm{C}$ ). Rainfall in general is scarce, mostly falling in spring. Annual rainfall varies from 350 to $450 \mathrm{~mm}$, with an average relative humidity of $66 \%$. 'Farga' was grown in La Terra Alta (altitude $286 \mathrm{~m}$ ), a region situated in the province of Tarragona (Catalonia, Spain) and characterized by an annual rainfall of 500 $\mathrm{mm}$ in a typical dry summer Mediterranean climate, although the differences between the maximum and minimum values are lower than in the Lleida region (actual temperature ranges from a minimum of $-3{ }^{\circ} \mathrm{C}$ to a maximum of $35^{\circ} \mathrm{C}$ ).

The two cultivars were sampled during the development period of the fruit (July-November), from fruit set to harvest time. The fruit were picked from all around the perimeter of the trees and taken to the laboratory for analysis.

RIPENESS INDEX. Ripeness was determined according to the proposals of Hermoso et al. (1991), based on the assessment of the skin color of 100 olives randomly drawn from $1 \mathrm{~kg}$ and divided into eight groups according to the pigmentation extent $(0-7)$ of the epicarp and mesocarp of the drupes: intense green, yellowish-green, green with reddish spots, reddish-brown, black with white flesh, black with $50 \%$ purple flesh, black with $50 \%$ purple flesh, and black with $100 \%$ purple flesh. The index is expressed as $\Sigma\left(N_{i} n_{i}\right) / 100$, where $N$ is the group number and $n$ is the fruit number in that group.

WATER AND FAT CONTENTS. The moisture content of the olive pulp was determined according to the Spanish standard method (Asociación Española de Normalización y Certificación, 1973). Samples of approximately $10 \mathrm{~g}$ were weighed, then dried for 24 $\mathrm{h}$ at $105^{\circ} \mathrm{C}$, cooled for $30 \mathrm{~min}$ in a desiccator and re-weighed.

Pigment extraction. Pigments were extracted from the olive fruit following the procedure described by Mínguez-Mosquera and Garrido-Fernández (1989). Samples of 5 to $30 \mathrm{~g}$ of stoned fruit, according to the degree of ripeness, were triturated for 1 min in a beater vessel containing $100 \mathrm{~mL}$ of dimethyl formamide (DMF) saturated with $\mathrm{MgCO}_{3}$. This solution was filtered and the operation repeated until the filtrates were colorless. The extracts were combined and transferred to a funnel containing $70 \mathrm{~mL}$ of hexane where they were shaken and left until the phases had separated. The two phases, hexane and DMF, were treated separately. The $N, N$-DMF phase was treated with hexane and $10 \%$ $\mathrm{NaCl}$ solution. Finally, ethyl ether was added, it was shaken, and held until the phases had separated. The ether phase with the chloroplast pigment solution was washed three times with an aqueous solution of $\mathrm{Na}_{2} \mathrm{SO}_{4}(2 \%)$ at $0{ }^{\circ} \mathrm{C}$. This solution was concentrated in a rotary evaporator at reduced pressure. The dry residue was dissolved in $1 \mathrm{~mL}$ of acetone.

The final dried hexane residue was eluted in a known volume of hexane to measure the $\beta$-carotene concentration directly, using the coefficient of extinction $\mathrm{E}^{1 \%}{ }_{454 \mathrm{~nm}}=2592$ (Foppen, 1971).

To identify the other isomers of carotene, the carotenoid pigments were saponified with the following extraction process. The hexane phases were mixed in a funnel and saponified with 100 $\mathrm{mL}$ of $15.6 \% \mathrm{KOH}$ in methanol. After $1 \mathrm{~h}$, distilled water was added and left until the phases had separated. The ether phase with the carotene fraction was washed three times with water and another three times with an aqueous solution of $\mathrm{Na}_{2} \mathrm{SO}_{4}$. It was concentrated by rotary evaporation at reduced pressure. The final residue was dissolved in $1 \mathrm{~mL}$ of acetone.

The chlorophyll and carotene solutions were stored in the dark in a freezer at $-30^{\circ} \mathrm{C}$ for high-performance liquid chromatography (HPLC) analyses. All extractions were performed in triplicate under a green light to prevent pigment alteration.

HPLC ANALYSIS OF PIGMENTS. The HPLC system was made up of a Waters 717 plus Autosampler, a 600 pump, a column heater module, and a Waters 996 photodiode array detector (Waters Inc., Milford, Mass.).

The column was a Spherisorb ODS-2 column and a Spherisorb S5 ODS-2 pre-column (Teknokroma, Barcelona, Spain) (Mínguez-Mosquera et al., 1992). Separation was performed using an elution gradient (flow rate $=2 \mathrm{~mL} \cdot \mathrm{min}^{-1}$ ) with the mobile phases (A) water/ion pair reagent $(0.05 \mathrm{M}$ tetrabutylammonium acetate and $1 \mathrm{M}$ ammonium acetate in water): methanol (1:1:8 by volume) and (B) methanol: acetone (1:1 by volume). Detection 
was performed at $430 \mathrm{~nm}$ (to measure chlorophyll $a$ ), $435 \mathrm{~nm}$ (to measure chlorophyllide $a$ ), $440 \mathrm{~nm}$ (for neoxanthin, violaxanthin, and esterified xanthophylls), $445 \mathrm{~nm}$ (for antheraxanthin, lutein and $\alpha$-carotene $), 452 \mathrm{~nm}$ ( $\beta$-cryptoxanthin $), 454 \mathrm{~nm}(\beta$-carotene $)$, $466 \mathrm{~nm}$ (chlorophyll $b$ ) and $468 \mathrm{~nm}$ (to measure chlorophyllide $b$ ). All peaks were identified by their chromatographic and spectroscopic characteristics.

External standard calibration was used for quantification. Chlorophylla (No. C-6144 from Synechococcus nidulans (Pringsheim) Komárek, chlorophyll $b$ (no. C-5878 from Spinacia oleracea L.) and $\beta$-carotene (No. C-4582) were supplied by Sigma (St. Louis). Chlorophyllides $a$ and $b$ were obtained from the respective solutions of chlorophylls by enzymatic de-esterification (Jones et al., 1972). The enzymatic extract of Chlase was obtained from Ailanthus altissima (Miller) Swingle leaves (Terpstra and Lambers, 1983). Lutein, violaxanthin, and neoxanthin were obtained from a pigment extract of fresh spinach (S. oleracea) and separated by thin-layer chromatography (TLC) on silica gel $\mathrm{GF}_{254}(0.2 \mathrm{~mm})$ on $20 \times 20 \mathrm{~cm}$ plates using petroleum ether $\left(65\right.$ to $\left.95^{\circ} \mathrm{C}\right) /$ acetone / diethylamine (10:4:1 by volume) (Minguez-Mosquera et al., 1992). Standards of antheraxanthin and $\beta$-cryptoxanthin were obtained from a saponified extract of red pepper (C. annuum) using HPLC for separation and quantification (Mínguez-Mosquera and Hornero-Mendez, 1993). Individual pigments were recorded on an olive drupe dry weight basis $\left(\mathrm{mg} \cdot \mathrm{kg}^{-1} \mathrm{DW}\right)$.

Pigment identification. Spectrophotometric and chromatographic properties permit the identification of the pigments. The spectral absorption maxima in different solvents, peak ratios and TLC and HPLC chromatography with authentic samples were used to identify pigments (Mínguez-Mosquera, 1997).

Preparation OF ACETONE POWDER. Thirty grams of lyophilized olive pulp was ground with $600 \mathrm{~mL}$ of acetone at $-20^{\circ} \mathrm{C}$ using a Polytron homogenizer (Kinematica AG, Lucerne, Switzerland) for some seconds. This mixture, together with $200 \mathrm{~mL}$ of distilled water, $0.5 \mathrm{~g}$ of polyethylene glycol (PEG) 2000, and 0.5 $\mathrm{g}$ of PEG 20000, was shaken for $8 \mathrm{~min}$ at $0{ }^{\circ} \mathrm{C}$ and filtered in a vacuum through filter paper. The residue was extracted, on one hand with $200 \mathrm{~mL}$ of ether and in the second place with $400 \mathrm{~mL}$ of methanol: acetone (1:1 by volume), filtered in a vacuum and extracted repeatedly with cold acetone: water ( $3: 1$ by volume) until the washing solution turned colorless. The last extraction was done only with cold acetone. Finally, the white residue, designated as acetone powder, was dried at room temperature, weighed, and stored at $-20^{\circ} \mathrm{C}$.

Extraction and assay of Chlase activity. Chlase activity in the crude enzyme extracts was assayed following the procedure described by Mínguez-Mosquera et al. (1994). One gram of acetone powder was added to $30 \mathrm{~mL}$ of extraction buffer ( 5 mu sodium phosphate buffer $\mathrm{pH} 7.0,50 \mathrm{~mm} \mathrm{KCl,} 0.24 \%$ octyl phenol ethoxylate as nonionic surfactant (Triton-X 100; SPI Supplies, West Chester, Pa.). The suspension was shaken for $1 \mathrm{~h}$ at $30{ }^{\circ} \mathrm{C}$ and then filtered through gauze. Afterwards, the filtrate was centrifuged at $12,000 \mathrm{~g}_{\mathrm{n}}$ for $10 \mathrm{~min}$ at $4{ }^{\circ} \mathrm{C}$. The supernatant, stored on ice, was used as a source of crude enzyme.

The assay mixture consisted of $100 \mathrm{~mm}$ Tris buffer $(0.5 \mathrm{~mL}$; $\mathrm{pH} 8.5)$ containing Triton-X $100\left(2.4 \mathrm{~g} \cdot \mathrm{L}^{-1}\right)$, crude Chlase extract $(0.5 \mathrm{~mL})$ and the reaction was initiated by adding $0.1 \mathrm{~mL}$ of a solution $0.1 \mu \mathrm{mol}$ of chlorophyll $a$ (Sigma). Eppendorfs were incubated at $40^{\circ} \mathrm{C}$ in the dark for $3 \mathrm{~h}$. The reaction was stopped by freezing the mixture to $-20{ }^{\circ} \mathrm{C}$ until required. Triplicate assays were performed for each extract. Before analysis, the mixture was centrifuged at $13,000 g_{\mathrm{n}}$ for $5 \mathrm{~min}$, and $40 \mu \mathrm{L}$ of supernatant was analyzed by HPLC, as above. Chlase enzymatic activity was expressed as nanomoles of substrate hydrolyzed per second. The results are expressed as specific activity, nanomoles per second per kilogram olive drupe dry weight.

Extraction AND ASSAY of Lox ACTIVITy. To analyze Lox activity, $400 \mathrm{mg}$ of acetone powder was homogenized in $15 \mathrm{~mL}$ of extraction buffer ( $0.2 \mathrm{M}$ sodium phosphate buffer $\mathrm{pH} 7.0$ with $0.1 \mathrm{~g}$ of $\mathrm{NaCl}$ ). The suspension was shaken for $20 \mathrm{~min}$ at $4{ }^{\circ} \mathrm{C}$. The homogenate was centrifuged at $12,000 \mathrm{~g}_{\mathrm{n}}$ for $15 \mathrm{~min}$ at $4{ }^{\circ} \mathrm{C}$. The supernatant, stored on ice, was filtered through glass wool and used as crude enzyme extract.

The Lox activity in the crude enzyme extracts was assayed using the method described by Surrey (1964). Lox enzymatic activity was expressed as nanomoles of product formed per second, calculated from the molar extinction coefficient of hydroperoxide $\left(\varepsilon=25,000 \mathrm{M}^{-1} \cdot \mathrm{cm}^{-1}\right)$ that corresponds to the absorbance of a 1 M solution performed in a $1-\mathrm{cm}$ path length quartz cuvette. The results are expressed as specific activity, nanomoles per second per kilogram olive drupe dry weight.

Statistical analysis. Statistical procedures were carried out with SAS (version 8.02; SAS Institute Inc., Cary, N.C.) to evaluate the differences between the olive cultivar and the stages of fruit development. Separation of the means was obtained using the least significant difference test, and significant difference was defined as $P \leq 0.05$.

\section{Results and Discussion}

The individual chloroplast pigments identified and the average concentrations (milligrams per kilogram dry weight) in fruit from 'Arbequina' and 'Farga' from the setting period to harvest time are presented in Tables 1 and 2, respectively. Sampling began in both cultivars at the end of the stone-hardening stage. 'Farga' is an early-ripening cultivar where drupe coloring begins sooner than in 'Arbequina' and this was reflected in the precocious coloring of the peel, red spots on the peel appearing sooner. There was no homogeneous maturation in 'Arbequina' since olives from three different ripening indexes could be seen on the same olive tree throughout the ripening period. In order to minimize these differences between the two cultivars, for each sampling date the fruit were picked from all around the perimeter of the tree, selecting fruit with a similar ripeness index based on the color of the skin.

The qualitative lipid-soluble pigments profile of the olive fruit was made up of chlorophyll $a$, chlorophyll $b$, and the carotenoids that typically accompany the chlorophylls in the chloroplast, such as lutein, all-trans- $\beta$-carotene, violaxanthin, neoxanthin, and antheraxanthin. Besides these, additional pigments were found only in 'Arbequina' fruit. These included cis- $\alpha$-carotene, $\beta$-cryptoxanthin, esterified xanthophylls, and chlorophyllides $a$ and $b$. The presence of these exclusive pigments is in accordance with Gandul-Rojas et al. (1999), who proposed that chlorophyllides could be used, with other pigments such as esterified xanthophylls and cis- $\alpha$-carotene, as a chemical-taxonomic identifier of 'Arbequina'. However, these previous studies (Gandul-Rojas et al., 1999; Roca and Mínguez-Mosquera, 2003) were carried out with 'Arbequina' fruits growing in the south of Spain, corresponding to an olive-growing area with different edaphologic characteristics and climatological conditions than those growing areas used in the present study. Thus, this chemical-taxonomic differentiator could be independent of the growing area of the olive tree.

During fruit set, pit hardening, and at the different stages of 
Table 1. Chlorophyll and carotenoid pigments in olive fruit from 'Arbequina' during the development of the fruit, from the fruit-setting period to harvesting time.

\begin{tabular}{|c|c|c|c|c|c|c|c|c|}
\hline \multirow[b]{2}{*}{$\begin{array}{l}\text { Picking date } \\
\text { (ripeness index)y: }\end{array}$} & \multicolumn{8}{|c|}{ Pigment content (mg.kg-1 DW of fruit) ${ }^{z}$} \\
\hline & $\begin{array}{c}5 \text { Aug. } \\
\text { (pit hardening) }\end{array}$ & $\begin{array}{c}27 \text { Aug. } \\
\text { (0) }\end{array}$ & $\begin{array}{c}16 \text { Sept. } \\
\text { (1) }\end{array}$ & $\begin{array}{l}5 \text { Oct. } \\
(1.5)\end{array}$ & $\begin{array}{l}15 \text { Oct. } \\
\text { (2) }\end{array}$ & $\begin{array}{c}22 \text { Oct. } \\
\text { (3) }\end{array}$ & $\begin{array}{l}15 \text { Nov. } \\
(5)\end{array}$ & $\begin{array}{c}26 \text { Nov. } \\
\text { (6) }\end{array}$ \\
\hline Chlorophyll $a$ & $363.4 \mathrm{a}$ & $270.7 \mathrm{~b}$ & $170.7 \mathrm{c}$ & $102.1 \mathrm{~d}$ & $47.5 \mathrm{e}$ & $30.2 \mathrm{f}$ & $4.73 \mathrm{~g}$ & $0.803 \mathrm{~g}$ \\
\hline Chlorophyll $b$ & $114.4 \mathrm{a}$ & $96.5 \mathrm{~b}$ & $56.5 \mathrm{c}$ & $31.1 \mathrm{c}$ & $16.2 \mathrm{e}$ & $11.0 \mathrm{f}$ & $1.68 \mathrm{~g}$ & $0.290 \mathrm{~g}$ \\
\hline Chlorophyllide $a$ & $9.47 \mathrm{a}$ & $1.80 \mathrm{bc}$ & $9.13 \mathrm{a}$ & $4.70 \mathrm{c}$ & $1.81 \mathrm{bc}$ & $0.986 \mathrm{~b}$ & ND & ND \\
\hline Chlorophyllide $b$ & $0.661 \mathrm{a}$ & $0.182 \mathrm{bc}$ & $0.819 \mathrm{a}$ & $0.253 \mathrm{c}$ & $0.095 \mathrm{bcd}$ & $0.071 \mathrm{bcd}$ & ND & ND \\
\hline Total chlorophylls & $487.9 \mathrm{a}$ & $369.2 \mathrm{~b}$ & $237.1 \mathrm{c}$ & $138.2 \mathrm{~d}$ & $65.6 \mathrm{e}$ & $42.3 \mathrm{f}$ & $6.41 \mathrm{~g}$ & $1.09 \mathrm{~g}$ \\
\hline Neoxanthin & $11.6 \mathrm{a}$ & $9.13 \mathrm{~b}$ & $6.80 \mathrm{c}$ & $3.22 \mathrm{~d}$ & $1.92 \mathrm{e}$ & $1.48 \mathrm{f}$ & $0.116 \mathrm{~g}$ & $0.044 \mathrm{~g}$ \\
\hline Violaxanthin & $15.4 \mathrm{a}$ & $4.69 \mathrm{~b}$ & $7.30 \mathrm{c}$ & $5.32 \mathrm{~b}$ & $2.90 \mathrm{~d}$ & $2.07 \mathrm{~d}$ & $0.293 \mathrm{e}$ & $0.094 \mathrm{e}$ \\
\hline Antheraxanthin & $4.39 \mathrm{a}$ & $3.54 \mathrm{~b}$ & $2.48 \mathrm{c}$ & $2.58 \mathrm{c}$ & $1.10 \mathrm{~d}$ & $0.703 \mathrm{e}$ & $0.168 \mathrm{f}$ & $0.085 \mathrm{f}$ \\
\hline Lutein & $46.7 \mathrm{a}$ & $49.6 \mathrm{~b}$ & $24.4 \mathrm{c}$ & $16.9 \mathrm{~d}$ & $8.02 \mathrm{e}$ & $6.73 \mathrm{e}$ & $1.86 \mathrm{f}$ & $1.05 \mathrm{f}$ \\
\hline$\beta$-cryptoxanthin & ND & ND & ND & ND & $0.045 \mathrm{a}$ & $0.032 \mathrm{~b}$ & $0.010 \mathrm{c}$ & ND \\
\hline Viol. monoest. ${ }^{x}$ & ND & $0.078 \mathrm{a}$ & $0.072 \mathrm{a}$ & $0.119 \mathrm{~b}$ & $0.179 \mathrm{c}$ & $0.152 \mathrm{~d}$ & ND & ND \\
\hline Neoxanthin esterified & ND & ND & 0.042 & ND & ND & ND & ND & ND \\
\hline all-trans- $\beta$-carotene & $13.6 \mathrm{a}$ & $14.6 \mathrm{~b}$ & $8.99 \mathrm{c}$ & $5.14 \mathrm{~d}$ & $2.87 \mathrm{e}$ & $3.06 \mathrm{e}$ & $0.852 \mathrm{f}$ & $0.438 \mathrm{f}$ \\
\hline cis- $\alpha$-carotene & $0.035 \mathrm{a}$ & $0.129 \mathrm{~b}$ & $0.013 \mathrm{c}$ & $\operatorname{tr}$ & $\operatorname{tr}$ & $\operatorname{tr}$ & $\operatorname{tr}$ & $\operatorname{tr}$ \\
\hline Total carotenoids & $91.7 \mathrm{a}$ & $81.6 \mathrm{~b}$ & $50.1 \mathrm{c}$ & $33.3 \mathrm{~d}$ & $17.0 \mathrm{e}$ & $14.2 \mathrm{f}$ & $3.30 \mathrm{~g}$ & $1.71 \mathrm{~g}$ \\
\hline Total pigments & $579.6 \mathrm{a}$ & $450.8 \mathrm{~b}$ & $287.2 \mathrm{c}$ & $171.5 \mathrm{~d}$ & $82.6 \mathrm{e}$ & $56.5 \mathrm{f}$ & $9.71 \mathrm{~g}$ & $2.80 \mathrm{~g}$ \\
\hline Chl. $a:$ chl. $b^{\mathrm{w}}$ & $3.18 \mathrm{a}$ & $2.81 \mathrm{bc}$ & $3.02 \mathrm{~d}$ & $3.28 \mathrm{a}$ & $2.93 \mathrm{~cd}$ & $2.75 \mathrm{~b}$ & $2.82 \mathrm{bc}$ & $2.77 \mathrm{bc}$ \\
\hline Lutein $: \beta$-carotene & $3.43 \mathrm{a}$ & $3.40 \mathrm{a}$ & $2.71 \mathrm{~b}$ & $3.29 \mathrm{ac}$ & $2.79 \mathrm{bc}$ & $2.20 \mathrm{bd}$ & $2.18 \mathrm{~d}$ & $2.40 \mathrm{~d}$ \\
\hline Chl. : carot.v & $5.32 \mathrm{a}$ & $4.52 \mathrm{~b}$ & $4.73 \mathrm{c}$ & $4.15 \mathrm{~d}$ & $3.86 \mathrm{~d}$ & $2.98 \mathrm{e}$ & $1.94 \mathrm{f}$ & $0.637 \mathrm{~g}$ \\
\hline
\end{tabular}

${ }^{2}$ Different letters within the same row indicate a significant difference by LSD test at $P<0.05$; SD was lower than 5\% (n $=3$ ); ND $=$ not detected; $\operatorname{tr}=$ trace amounts.

yRipeness index: $0=$ intense green; $1=$ green; $1.5=$ yellowish green; $2=$ green with reddish spots; $3=$ reddish-brown; $5=$ black with $50 \%$ purple flesh, 6 = black with $50 \%$ purple flesh.

$\mathrm{x}$ Viol. monoest. $=$ Monoesterified violaxanthin.

wChlorophyll $a$ : chlorophyll $b$ ratio.

'Chlorophyll: carotenoid ratio.

Table 2. Chlorophyll and carotenoid pigments in olive fruit from 'Farga' during the development of the fruit, from the fruit-setting period to harvesting time.

\begin{tabular}{|c|c|c|c|c|c|c|}
\hline \multirow[b]{2}{*}{$\begin{array}{l}\text { Picking date } \\
\text { (ripeness index)y: }\end{array}$} & \multicolumn{6}{|c|}{ Pigment content $\left(\mathrm{mg} \cdot \mathrm{kg}^{-1} \mathrm{DW} \text { of fruit }\right)^{\mathrm{z}}$} \\
\hline & $\begin{array}{c}30 \text { July } \\
\text { (pit hardening) }\end{array}$ & $\begin{array}{l}10 \text { Aug. } \\
(0)\end{array}$ & $\begin{array}{c}24 \text { Aug. } \\
\text { (0) }\end{array}$ & $\begin{array}{l}21 \text { Sept. } \\
\text { (1) }\end{array}$ & $\begin{array}{c}22 \text { Oct. } \\
\text { (3) }\end{array}$ & $\begin{array}{l}24 \text { Nov. } \\
\text { (6) }\end{array}$ \\
\hline Chlorophyll $a$ & $394.0 \mathrm{a}$ & $354.1 \mathrm{~b}$ & $279.4 \mathrm{c}$ & $148.2 \mathrm{~d}$ & $38.1 \mathrm{e}$ & $0.326 \mathrm{f}$ \\
\hline Chlorophyll $b$ & $141.1 \mathrm{a}$ & $128.0 \mathrm{~b}$ & $106.0 \mathrm{c}$ & $60.6 \mathrm{~d}$ & $15.1 \mathrm{e}$ & $0.168 \mathrm{f}$ \\
\hline Total chlorophylls & $535.1 \mathrm{a}$ & $482.1 \mathrm{~b}$ & $385.4 \mathrm{c}$ & $208.8 \mathrm{~d}$ & $53.2 \mathrm{e}$ & $0.494 \mathrm{f}$ \\
\hline Neoxanthin & $11.6 \mathrm{a}$ & $10.6 \mathrm{~b}$ & $7.91 \mathrm{c}$ & $3.77 \mathrm{~d}$ & $0.809 \mathrm{e}$ & ND \\
\hline Violaxanthin & $17.2 \mathrm{a}$ & $14.4 \mathrm{~b}$ & $9.30 \mathrm{c}$ & $4.44 \mathrm{~d}$ & $0.913 \mathrm{e}$ & $0.010 \mathrm{f}$ \\
\hline Antheraxanthin & $3.13 \mathrm{a}$ & $3.07 \mathrm{a}$ & $2.61 \mathrm{~b}$ & $1.61 \mathrm{c}$ & $0.352 \mathrm{~d}$ & $0.023 \mathrm{~d}$ \\
\hline Lutein & $44.9 \mathrm{a}$ & $39.7 \mathrm{~b}$ & $33.5 \mathrm{c}$ & $18.8 \mathrm{~d}$ & $7.07 \mathrm{e}$ & $0.459 \mathrm{f}$ \\
\hline All-trans- $\beta$-carotene & $12.1 \mathrm{a}$ & $12.1 \mathrm{a}$ & $10.9 \mathrm{~b}$ & $5.62 \mathrm{c}$ & $2.03 \mathrm{~d}$ & $0.210 \mathrm{e}$ \\
\hline Total carotenoids & 88.9 a & $79.9 \mathrm{~b}$ & $64.2 \mathrm{c}$ & $34.2 \mathrm{~d}$ & $11.2 \mathrm{e}$ & $0.702 \mathrm{f}$ \\
\hline Total pigments & $624.0 \mathrm{a}$ & $562.0 \mathrm{~b}$ & $449.6 \mathrm{c}$ & $243.0 \mathrm{~d}$ & $64.4 \mathrm{e}$ & $1.20 \mathrm{f}$ \\
\hline Chl. $a:$ chl. $b^{\mathrm{x}}$ & $2.79 \mathrm{a}$ & $2.77 \mathrm{a}$ & $2.64 \mathrm{~b}$ & $2.45 \mathrm{c}$ & $2.52 \mathrm{c}$ & $1.94 \mathrm{~d}$ \\
\hline Lutein : $\beta$-carotene & $3.71 \mathrm{a}$ & $3.28 \mathrm{bc}$ & $3.07 \mathrm{~b}$ & $3.35 \mathrm{abc}$ & $3.48 \mathrm{ac}$ & $2.19 \mathrm{~d}$ \\
\hline Chl.: carot. ${ }^{w}$ & $6.02 \mathrm{a}$ & $6.03 \mathrm{a}$ & $6.00 \mathrm{a}$ & $6.11 \mathrm{a}$ & $4.75 \mathrm{~b}$ & $0.704 \mathrm{c}$ \\
\hline
\end{tabular}

${ }^{2}$ Different letters within the same row indicate a significant difference by LSD test $(P<0.05)$; SD was lower than 5\% (n $\left.=3\right)$; ND $=$ not detected. yRipeness index: $0=$ intense green; 1 = green; 3 = reddish-brown; $6=$ black with $50 \%$ purple flesh.

xChlorophyll $a$ : chlorophyll $b$ ratio.

wChlorophyll: carotenoid ratio. 
the ripening process, chlorophyll $a$ was the major chloroplast pigment, followed by chlorophyll $b$ in the olive drupes of the two cultivars studied. However, when the olive drupes reached the black stage, specifically at the end of November (ripeness index 6 ), coinciding with the harvest period for industrial oil production, lutein was the main pigment, probably as a consequence of its lower rate of degradation.

The total pigment content in the olive drupes from the two cultivars studied showed the same trend during development and ripening. The highest values were at the end of July, coinciding with the pit hardening of the olive fruit, and the lowest concentration of lipid-soluble pigments were in autumn, when the technological harvest period in the olive-growing area began (November). However, there were quantitative differences between the two olive cultivars studied in pigment content and pigment retention. When the biosynthesis process was complete, it was found that the fruit from 'Farga' were more pigmented than 'Arbequina', with values of $624 \mathrm{mg}$ total pigments per kilogram DW of fruit (Table 2) as opposed to $579.6 \mathrm{mg}$ per kilogram DW of fruit (Table 1).

During the ripening process, the gradual disintegration of the chloroplasts involves the disappearance of the chloroplast pigments. Although, when the biosynthesis of pigments was complete, the level of chlorophylls was approximately five times higher than that of the carotenoids in both cultivars (as can been seen in the chlorophyll : carotenoid ratio), during ripening the rate of chlorophyll degradation was more marked than that of the carotenoid pigment. In both cultivars, at the red color stage (ripeness index 3 ) during ripening the rate of decrease in total chlorophyll increased, but these pigments were still present in the black fruit (ripeness index 6), although masked by the other pigments, such as anthocyanins. At the beginning of the ripening period, when the olive drupe color turns from green to light green, chlorophylls $a$ and $b$ represented $83 \%$ of the total pigments in fruit from 'Arbequina' (Table 1), and 85\% in 'Farga' (Table 2), decreasing to $44 \%$ and $47 \%$ at the end of the maturity process, respectively. In both cultivars, lutein was the carotenoid that degraded slowest. The results of this study showed that the chlorophyll $a$ : chlorophyll $b$ ratio remained more or less constant throughout the development and ripening of the fruit in both cultivars, showing that chlorophyll $a$ and chlorophyll $b$ disappeared together, although chlorophyll $a$ degraded more rapidly than $b$. However, in 'Arbequina', this ratio was slightly higher than in 'Farga'. Nevertheless, studies carried out in the olive-growing area of Andalusia (southern Spain) with fruit from 'Arbequina' showed that during fruit ripening, this ratio was higher than observed in this study (Roca and Mínguez-Mosquera, 2001a, 2001b). Considering that chlorophyll $b$ is a constituent of the light-harvesting system and the reaction centers are rich in chlorophyll $a$ (Thomas, 1997), the lower sunlight availability for olive trees in the geographical area of this study could cause a greater development of the light-harvesting complex, relatively rich in chlorophyll $b$.

There were some differences in relation to the carotenoid fraction at the beginning of ripening between the two cultivars studied. In fruit of 'Arbequina', at the end of the pit hardening, when the skin color of fruit is green (ripening index 0 ), lutein, $\alpha$, and $\beta$-carotene con- tent increased and monoesterified violaxanthin became present. During the change from green to green-yellowish (ripening index 1) the violaxanthin content increased and esterified neoxanthin was detected, and at a ripeness index of 2 (skin green with reddish spots), $\beta$-cryptoxanthin was quantified (Table 1$)$. This synthesis of carotenoids was not observed in 'Farga' (Table 2). The carotenogenic process observed in this study confirmed the results of studies on 'Arbequina' cultivated in the olive-growing area in the south of Spain (Roca and Mínguez-Mosquera, 2001b). Consequently, it is possible to affirm that fruit from 'Arbequina' behave similarly to carotenogenic fruit, in which chloroplast changes into chromoplast during ripening and while chlorophylls disappear, an important synthesis of carotenoids occurs (Gross, 1991). Moreover, the presence of esterified xanthophylls in these fruit indicates that the chloroplast does not remain intact during the ripening process, but degenerates into chromoplast, characteristic of carotenogenic fruits.

Independently of the level reached, the pigment concentration decreased with fruit maturity in both cultivars (Fig. 1). The percentage of retention of chlorophylls and carotenoids, at the end of the green stage (October-November) was, respectively,
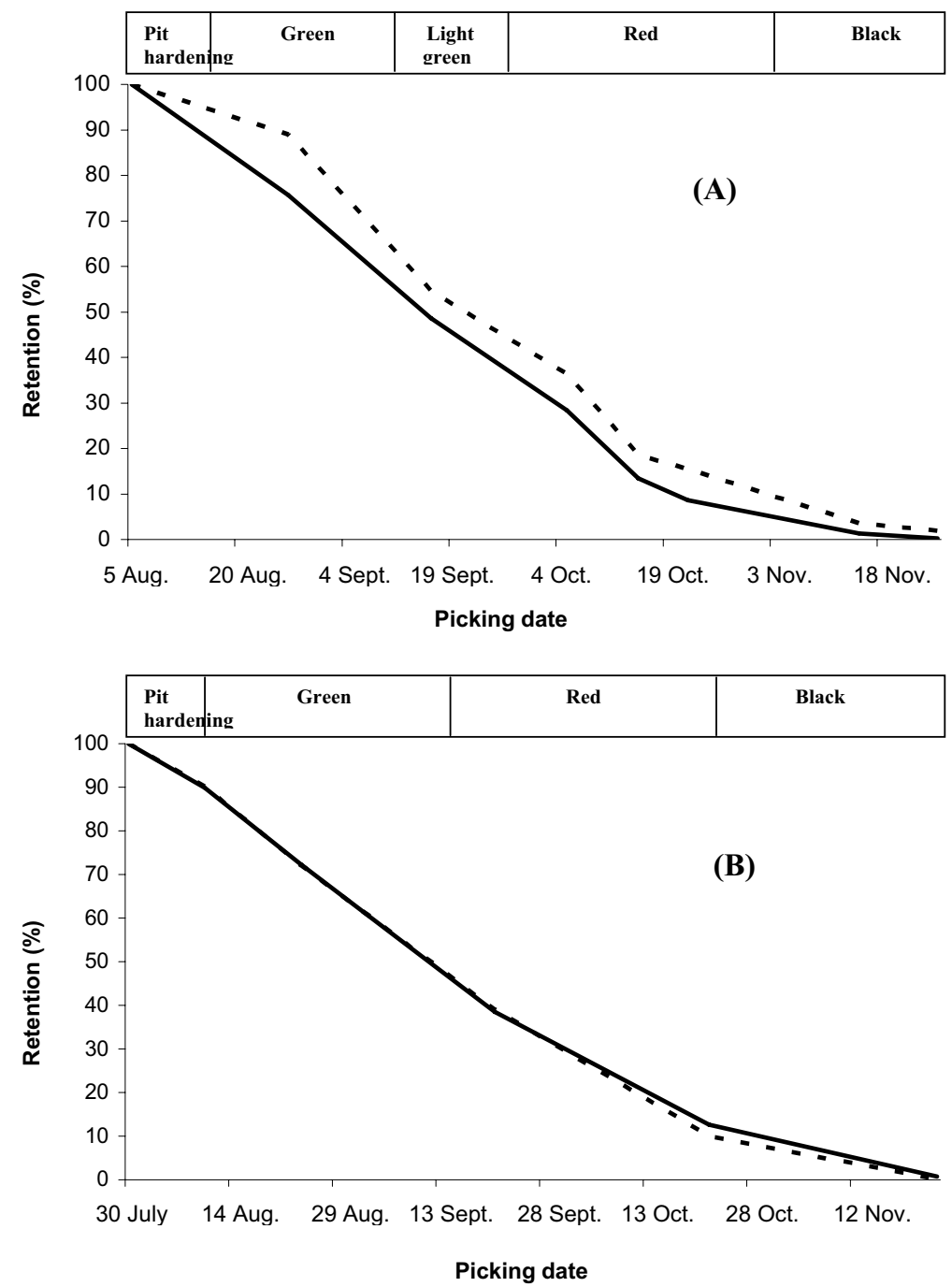

Fig. 1. Percentage of retention ofchlorophylls (-) and carotenoids (-- ) during the ripening stages of (A) 'Arbequina' and (B) 'Farga' olives. Retention 100\%: (A) total chlorophylls = $487.8 \mathrm{mg} \cdot \mathrm{kg}^{-1} \mathrm{DW}$ fruit, total carotenoids $=91.7 \mathrm{mg} \cdot \mathrm{kg}^{-1} \mathrm{DW}$ fruit; $(\mathbf{B})$ total chlorophylls $=535.1 \mathrm{mg} \cdot \mathrm{kg}^{-1} \mathrm{DW}$ fruit, total carotenoids $=88.9 \mathrm{mg} \cdot \mathrm{kg}^{-1} \mathrm{DW}$ fruit. 


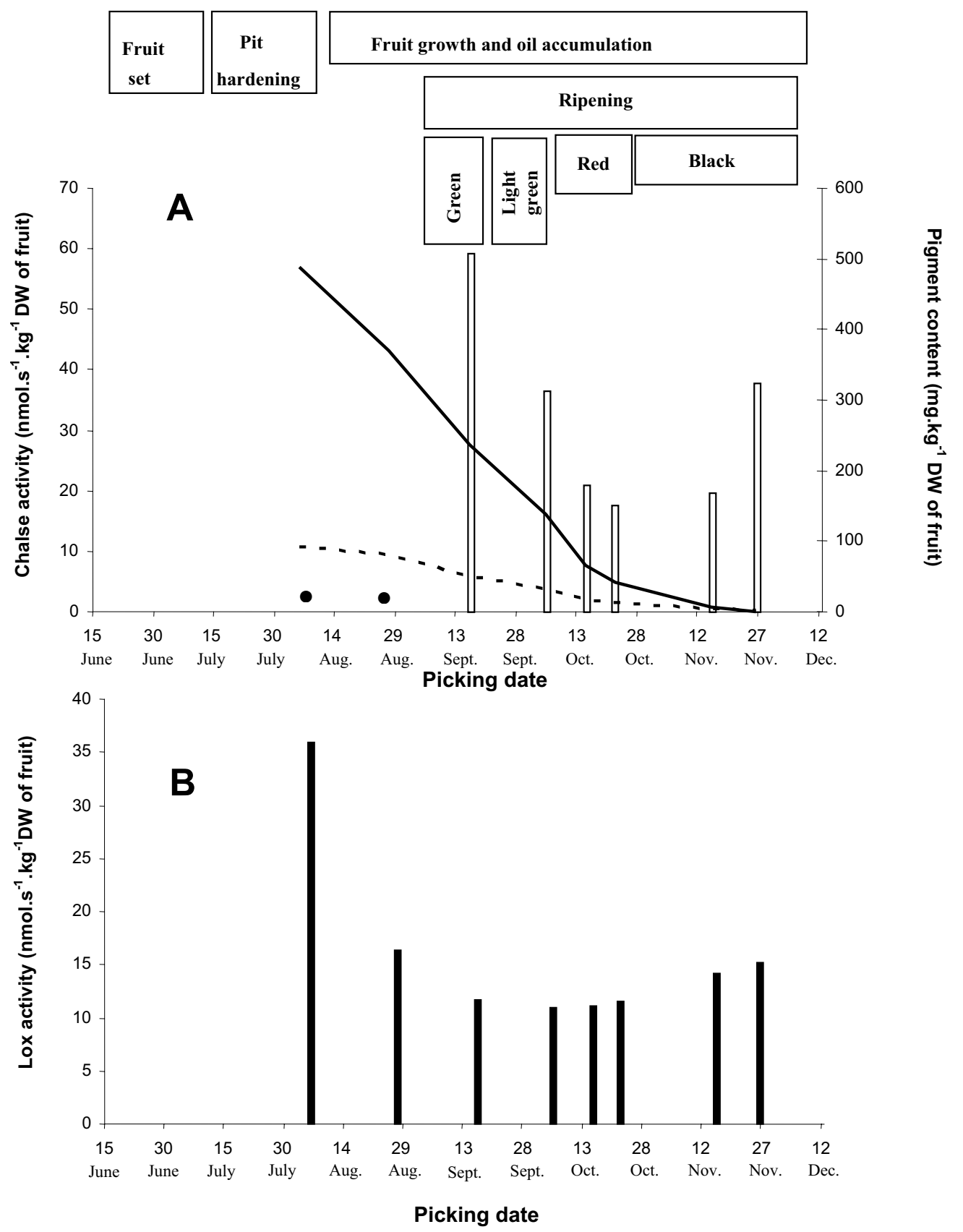

Fig. 2. (A) Changes in chlorophyll (-) and carotenoid ( - - - ) content; (B) chlorophyllase (Chlase )and lipoxygenase (Lox ) activity in 'Arbequina' olives during different phenological stages; $\boldsymbol{O}=$ no detected Chlase activity.

$8.7 \%$ and $15.5 \%$ for 'Arbequina' (Fig. 1A), and 9.9\% and $12.0 \%$ for 'Farga' (Fig. 1B). At the end of the ripening process (black stage) 'Arbequina' retained $0.22 \%$ and $1.86 \%$ of chlorophylls and carotenoids, respectively; while 'Farga' showed lower pigment retention, with $0.09 \%$ and $0.79 \%$. The rate of disappearance of both pigment fractions were similar in the two cultivars, although 'Arbequina' fruits showed a percentage of retention of carotenoids slightly superior to that of chlorophylls throughout fruit growing and maturation.

The regression analysis was carried out to evaluate the percentage of retention of chlorophylls and carotenoids in relation to picking date. Because the degree of fruit ripening has a strong effect on the percentage of retention of pigments in both cultivars, the slopes $(\mathrm{m})$ of the linear regression were different in relation to ripening periods. So, from the beginning of the ripening (green stage) to the final stage (black stage) the slopes of the rates of disappearance of chlorophylls were -1.19 for 'Arbequina' and -1.12 in 'Farga', and those of carotenoids were -1.17 in 'Arbequina' and -1.10 in 'Farga'. In the final stage of the fruit ripening (black stage) a slower rate of disappearance was observed, with slope values of -0.26 and -0.30 for the chlorophyllic fraction of 'Arbequina' and 'Farga', respectively, and -0.42 and -0.34 for the carotenoid fraction. The tendency in the decrease of chloroplastic pigments that has been observed in this study seems to follow a similar pattern to the one reported by Roca and Mínguez-Mosquera (2001a) in different Spanish cultivars. They assumed that the pattern of change of chloroplastic pigments consists of three steps: the first change of relative rate takes place when the synthesis 

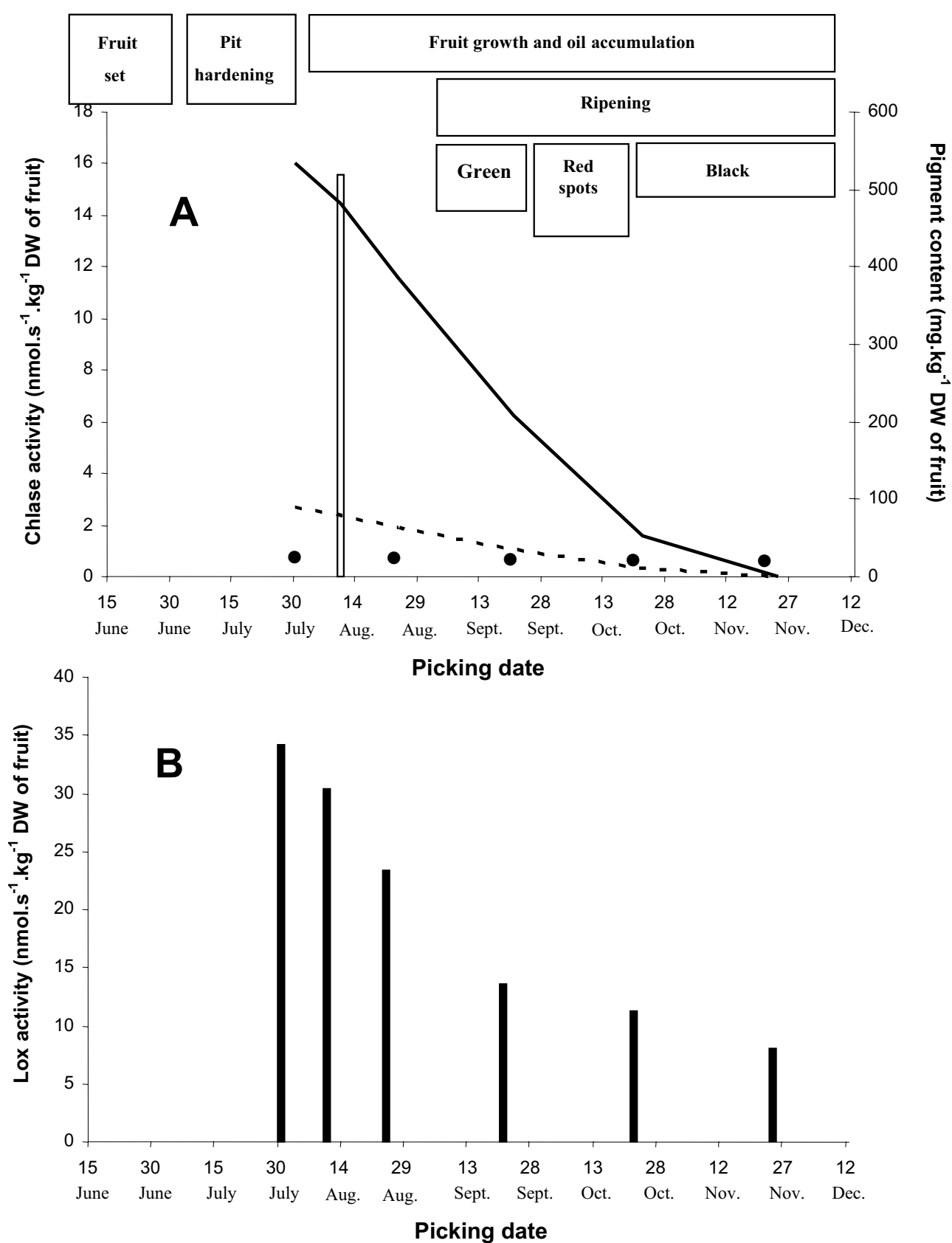

Fig. 3. (A) Changes in chlorophyll ( - ) and carotenoid ( - - ) content; (B) chlorophyllase (Chlase) and lipoxygenase (Lox ) activity in 'Farga' olives during different phenological stages; $\mathbf{0}=$ no detected Chlase activity.

of anthocyanins begins in the fruits, reddish mottles appearing in the olive skin; the next step would correspond to the moment when fruits show a cover of purple pigmentation; and the last step would be when that cover is black.

Figures 2 and 3 show the changes in the Chlase (EC 3.1.1.14) and Lox (EC 1.13.11.12) enzymatic activities and the total chlorophyll and carotenoid contents of olive drupes from the two cultivars studied from the fruit-setting period to harvest time. Chlase activity in the fruit of 'Arbequina' (Fig. 2) was not detected during the first sampling period (August) coinciding with the end of the pit-hardening and the beginning of the fruit-growing periods. The highest Chlase activity was observed during the first steps of the olive ripening and this could explain the presence of chlorophyllides $a$ and $b$ in fruit from this cultivar (Table 1). When the skin color of the fruit changed from green to light green, both the chlorophyll content and Chlase activity in the whole fruit decreased and the lowest values were reached at the red stage, when the activity fell by $70 \%$ from the initial value, and at the end of the ripening process, the enzymatic activity increased from 18 to $38 \mathrm{nmol} \cdot \mathrm{s}^{-1} \cdot \mathrm{kg}^{-1} \mathrm{dry}$ weight of fruit coinciding with harvest period for olive oil extraction. By contrast, Chlase activity in 'Farga' was detected only at the end of the pit-hardening period (Fig. 3) when the olive fruit was not yet developed and coinciding with the main degradation of chlorophylls. Decreasing Chlase activity during fruit ripening (low values in 'Arbequina' and disappearance of this activity in 'Farga') may indicate that other enzymes were involved in the rapid disappearance of chlorophylls. Moreover, it is significant that in 'Arbequina' with high levels of Chlase, the rate of disappearance of chlorophylls was slightly less than that recorded in 'Farga', in which Chlase was practically absent. 
The evolution of the Lox activity was similar in both cultivars and it was marked at the end of the pit-hardening process, coinciding with the maximum pigment concentration (Figs. 2 and 3). However, although the highest values of Lox activity coincided with the phase of steepest fruit growth, the low proportion of linoleic and linolenic acids, which are substrates of this enzyme, did not create adequate conditions for its action. Later, the enzyme activity began to fall when fruit growth slowed and ripening advanced. The behavior of this enzyme was the same as for Chlase in 'Arbequina', showing a slight increase of activity at the latest stages of ripening (Fig. 2).

From the results observed in this study, we have to conclude that the differences in the lipophilic pigment content, and Chlase and Lox activity could be related to the varietal characteristics of the olive fruit, considering also the time of their respective ripening. Consequently, to explain the presence of exclusive pigments, the different rate of pigment disappearance in addition to the carotenogenic process in fruit from 'Arbequina', we should think of the difference in the structure of the photosynthetic apparatus in these two cultivars. Moreover, profiles for Chlase and Lox activities were clearly different. In the case of 'Arbequina', the pigment degradation during ripening could be due to both enzymatic activities. However, the important disappearance of chlorophylls observed in the fruit of 'Farga' could be attributed to this Lox activity more than to Chlase activity. The data obtained during the olive fruit development indicate that pigment content and composition, besides the Chlase and Lox actions, will be useful for biochemical characterization of different olive cultivars.

\section{Literature Cited}

Aljuburi,H.,A. Huff, and M. Hsheih. 1979. Enzymes of chlorophyll catabolism in orange flavedo. Plant Physiology 63, Suppl. 73:410-413.

Asociación Española de Normalización y Certificación. 1973. Determinación de humedad y materias volatiles. Norma Española UNE 55020. AENOR, Madrid, Spain.

Feussner, I. and C. Wasternack. 2002. The lipoxygenase pathway. Annu. Rev. Plant Biol. 53:275-297.

Foppen, F.H. 1971. Tables for identification of carotenoid pigments. Chromatography Rev. 14:133-298.

Gandul-Rojas, B., M.L.R. Cepero, and M.I. Mínguez-Mosquera. 1999. Chlorophyll and carotenoid patterns in olive fruits, Olea europaea cv. 'Arbequina'. J. Agr. Food Chem. 47:2207-2212.

Gallardo-Guerrero, L., M. Jarén-Galán, D. Hornero-Méndez, and M.I. Mínguez-Mosquera. 2003. Evidence for the involvement of lipoxygenase in the oxidative processes associated with the appearance of green staining alteration in the Gordal olive. J. Sci. Food Agr. 83:1487-1492.

Gandul-Rojas, B. and M.I. Mínguez-Mosquera. 1996. Chlorophyllase activity in olive fruits and its relationship with the loss of chlorophyll pigments in the fruits and oils. J. Sci. Food Agr. 72:291-294.

Gandul-Rojas, B., M. Roca, and M.I. Mínguez-Mosquera. 2004. Chlorophyll and carotenoid degradation mediated by thylakoid-associated peroxidative activity in olives (Olea europaea) cv. Hojiblanca. J. Plant. Physiol. 161:499-507.

Gross, J. 1991. Pigments in vegetables: Chlorophylls and carotenoids. Van Nostrand Reinhold, New York.
Hermoso, M., M. Uceda, A. García, B. Morales, M.L. Frías, and A. Fernández. 1991. Elaboración de aceite de calidad, Serie Apuntes 5/91. Editorial Junta de Andalucia, Consejería de Agricultura y Pesca, Seville, Spain.

Hornero-Méndez, D. and M.I. Mínguez-Mosquera. 2002. Chlorophyll disappearance and chlorophyllase activity during ripening of Capsicum annuum L. fruits. J. Sci. Food Agr. 82:1564-1570.

Jones, I.D., L.S. Butler, E. Gibbs, and R.C. White. 1972. An evaluation of reversed phase partition for thin-layer chromatography identification of chlorophylls and derivatives. J. Chromatography 70:87-98.

Matile, P. and S. Hörtensteiner. 1999. Chlorophylls degradation. Annu. Rev. Plant Physiol. Plant. Mol. Biol. 50:67-95.

Mínguez-Mosquera, M.I. 1997. Identificación de pigmentos, p. 111-154. In: M.I. Mínguez-Mosquera (ed.). Clorofilas y carotenoides en Tecnología de Alimentos. Universidad de Sevilla, Seville. Spain.

Mínguez-Mosquera, M.I., B. Gandul-Rojas, and L. Gallardo-Guerrero. 1992. Rapid method of quantification of chlorophylls and carotenoids in virgin olive oil by high performance liquid chromatography. J. Agr. Food Chem. 40:60-63.

Mínguez-Mosquera, M.I., B. Gandul-Rojas, and L. Gallardo-Guerrero. 1994. Measurement of chlorophyllase activity in olive fruit, J. Biochem. 116:263-268.

Mínguez-Mosquera, M.I. and J. Garrido-Fernández. 1989. Chlorophyll and carotenoid presence in olive fruit (Olea europea). J. Agr. Food Chem. 37:1-7.

Mínguez-Mosquera, M.I. and D. Hornero-Méndez. 1993. Separation and quantification of the carotenoid pigments in red peppers (Capsicum annuиm L.), paprika, and oleoresin by reversed-phase HPLC. J. Agr. Food Chem. 41:1616-1620.

Pagliarini, E., P. Stramba, and L. Semeria. 1994. Study of the subjective affective meaning and motivations aspects towards extra virgin olive oil. Grasas y Aceites 45:65-67.

Roca, M. and M.I. Mínguez-Mosquera. 2001a. Changes in chloroplast pigments of olive varieties during fruit ripening. J. Agr. Food Chem. 49:832-839.

Roca, M. and M.I. Mínguez-Mosquera. 2001b. Unusual carotenogenesis in fruits with pronounced anthocyanic ripening (Olea europaea var. “Arbequina”). J. Agr. Food Chem. 49:4414-4419.

Roca, M. and M.I. Mínguez-Mosquera. 2003. Involvement of chlorophyllase in chlorophyll metabolism in olive varieties with high and low chlorophyll content. Physiol. Plant. 117:459-466.

Salas, J.J., M. Williams, J.L. Harwood, and J. Sánchez. 1999. Lipoxygenase activity in olive (Olea europaea) fruit. J. Amer. Oil Chem. Soc. 76:1163-1168.

Shulman, Y. and S. Lavee. 1979. Endogenous cytokinins in maturing Manzanillo olive fruits. Plant Physiol. 57(4):490-492.

Surrey, K. 1964. Spectrophotometric method for determination of lipoxidase activity. Plant Physiol. 39:65-70.

Terpstra, W. and J.W.J.Lambers. 1983. Interactions between chlorophyllase, chlorophyll $a$, plants lipids and $\mathrm{Mg}^{2+}$. Biochim. Biophys. Acta 746(1-2):23-31.

Thomas, H. 1997. Chlorophyll $a$ : A symptom and a regulator of plastid development. New Phytol. 136:163-181.

Uceda, M. and M. Hermoso. 1997. La calidad del aceite de oliva, p. 547-572. In: D. Barranco, D. Fernández- Escobar, and L. Rallo (eds.). El cultivo del olivo. Mundi-Prensa. Madrid, Spain.

Yamauchi, N. and T. Minamide. 1985. Mechanism of chlorophyll degradation in harvested leaf vegetables. 1. Chlorophyll degradation by peroxidase in parsley leaves. J. Jpn. Soc. Hort. Sci. 54:265-271. 